Necessi ty of el ect romagnet i c fi el d comput at i on for the magnetic current li miter

\begin{tabular}{|c|c|}
\hline 著者 & $\begin{array}{l}\text { Mikhopdhy ay S. C., I wahar a Nasay oshi, Yamada } \\
\text { Sot oshi }\end{array}$ \\
\hline 著者別表示 & 岩原 正吉, 山田 外史 \\
\hline $\begin{array}{l}\text { journal or } \\
\text { publ i cat } i \text { on } t i t l e\end{array}$ & $\begin{array}{l}\text { Int er nat i onal J our nal of Appl i ed } \\
\text { El ect r onagnet i cs and Mechani cs }\end{array}$ \\
\hline vol une & 14 \\
\hline number & 1. 4 SPEC \\
\hline page $r$ ange & 47- 50 \\
\hline year & 2001 \\
\hline URL & ht t p: //doi . or g/10. 24517/00049207 \\
\hline
\end{tabular}




\title{
Necessity of electromagnetic field computation for the magnetic current limiter
}

\author{
S.C. Mukhopadhyay ${ }^{\mathrm{a}, *}$, M. Iwahara ${ }^{\mathrm{b}}$ and S. Yamada ${ }^{\mathrm{b}}$ \\ ${ }^{\mathrm{a}}$ Institute of Information Sciences and Technology, Massey University, Private bag 11222, Palmerston \\ North, NewZealand \\ ${ }^{\mathrm{b}}$ Faculty of Engineering, Kanazawa University, Kodatsuno 2-40-20, Kanazawa, 920, Japan
}

\begin{abstract}
For the last few years the authors have been involved in the design and development of different topologies of magnetic current limiter (MCL). The small scale laboratory models have been fabricated and experiments were conducted. The simulated performance obtained from the tableau approach based on lumped parameter model shows discrepancy with the experiment. This paper describes the necessity of electromagnetic field computation which clearly shows the discrepancy between the observed and the simulation results, which can be attributed to a non uniform flux distribution in the core.
\end{abstract}

\section{Introduction and topological configuration of magnetic current limiter}

The design and development of passive type magnetic current limiter based on a permanent magnet and saturable core has already been reported [1]. Figure 1 shows a schematic of an unipolar magnetic current limiter in which the permanent magnet (PM) biases the core. The magnetomotive force of the coil aids the PM mmf during the positive half and opposes it during the negative half of the ac cycle. During normal operation the saturated core has a very low impedance. During the fault condition the core comes out of saturation and has a large impedance which limits the fault current. Different topological models based on biasing mode, core material and supply system have been designed and fabricated in laboratory [2]. Figure 2 shows the fabricated model based on Neodium-Iron-Boron magnet and ferrite core in a series biasing mode and the half-assembly of the fabricated model of the series biased limiter based on steel core is shown in Fig. 3. Figure 4 shows the fabricated model of a parallel biased based on Nd-Fe-B magnet and steel core and the half-assembly of the fabricated model for three phase system based on circular magnet is shown in Fig. 5.

\section{Performance analysis and necessity of electromagnetic field computation}

The transient numerical analysis for the performance of the current limiter has been carried out by tableau approach which takes into account the combination of electric and magnetic circuits [3]. The magnetic circuit is represented by magnetic field strength of the permanent magnet and the lumped magnetic reluctances of the permanent magnet and the core. Figure 6 shows a comparison of the

${ }^{*}$ Corresponding author: S.C. Mukhopadhyay, Fax: +64 6350 5604; E-mail: S.C.Mukhopadhyay@massey,ac.nz. 


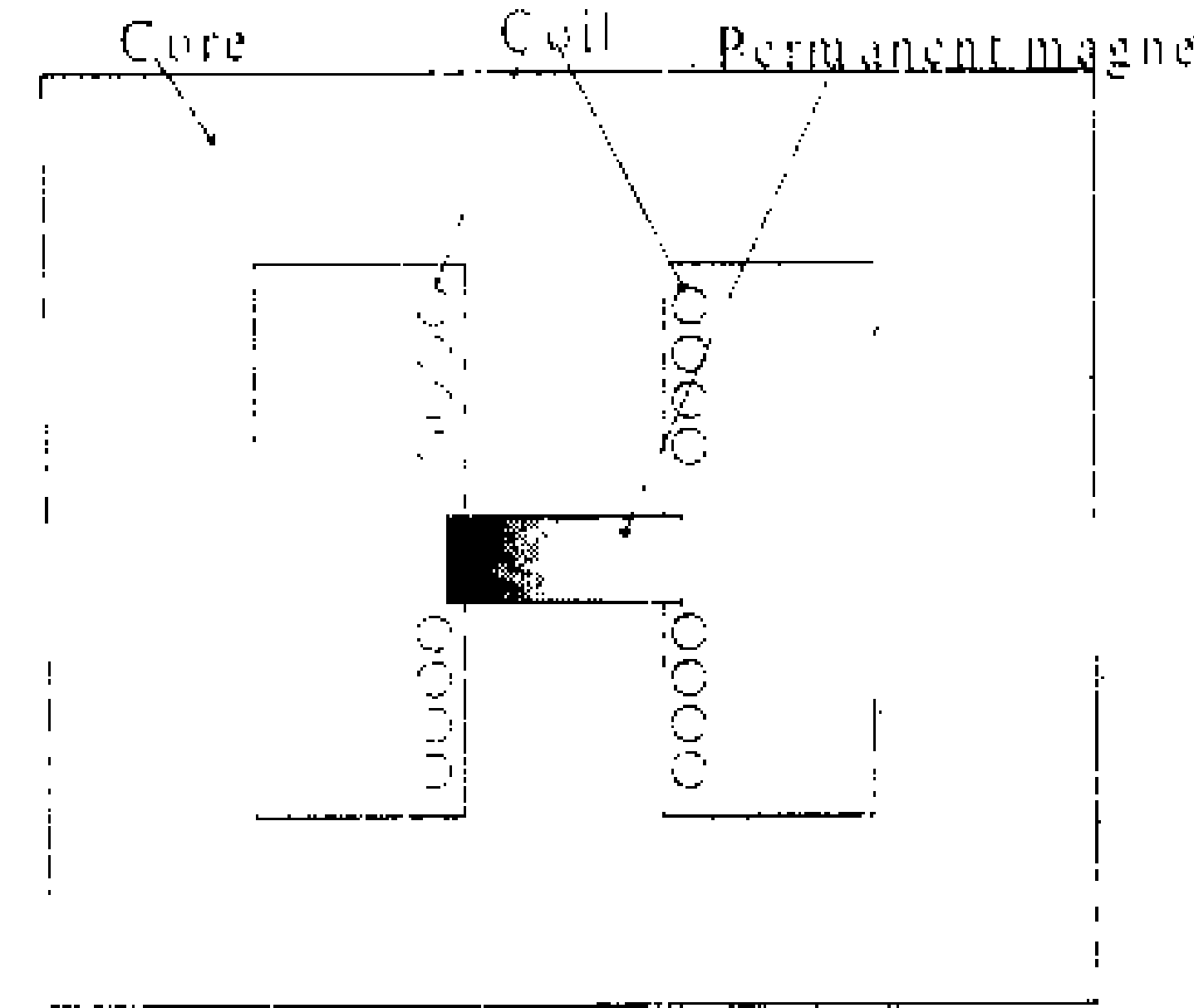

Fig. 1. Schematic of an unipolar magnetic clarrent limiter.

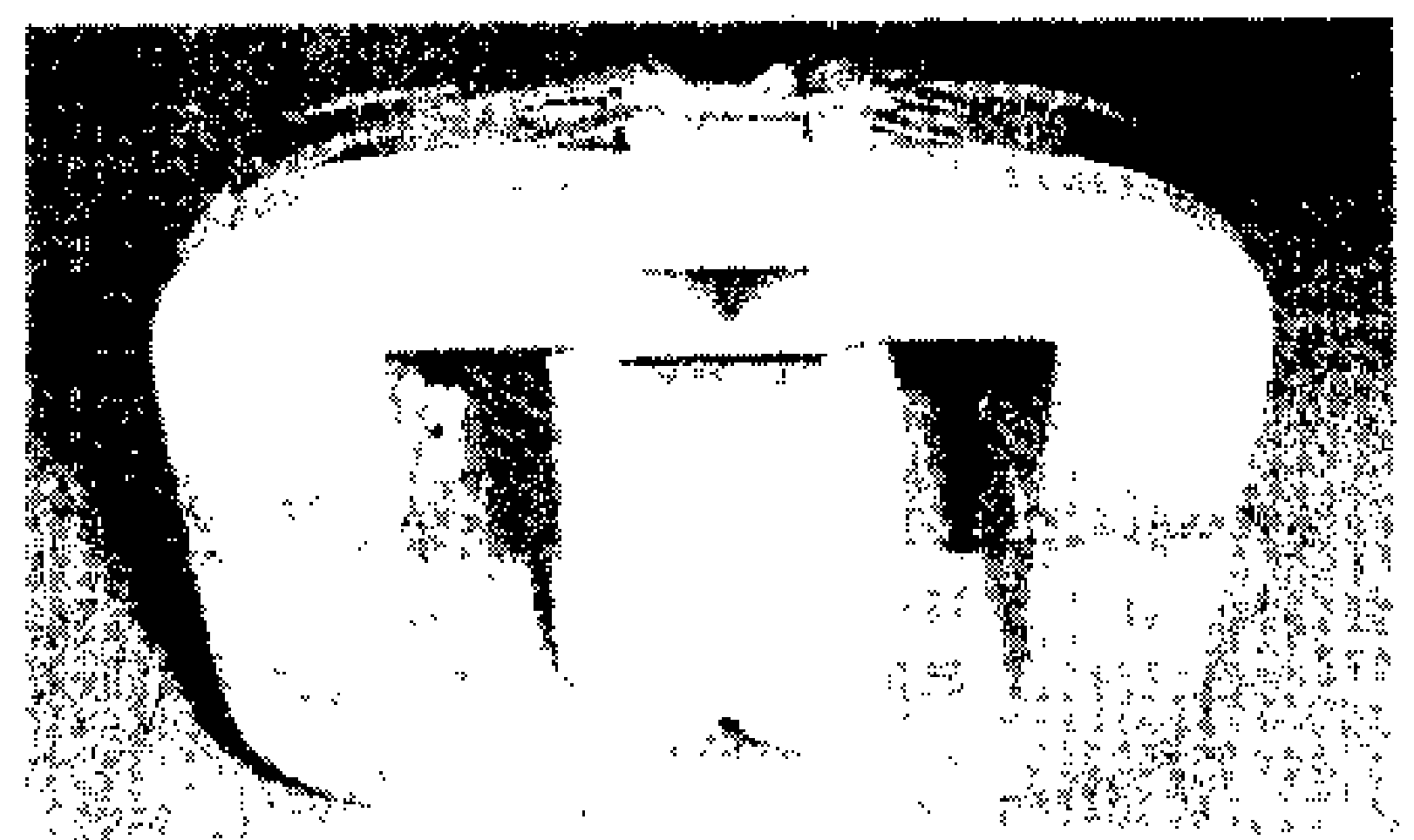

Fig. 3. Fabricated series-biased steel core based MCL.

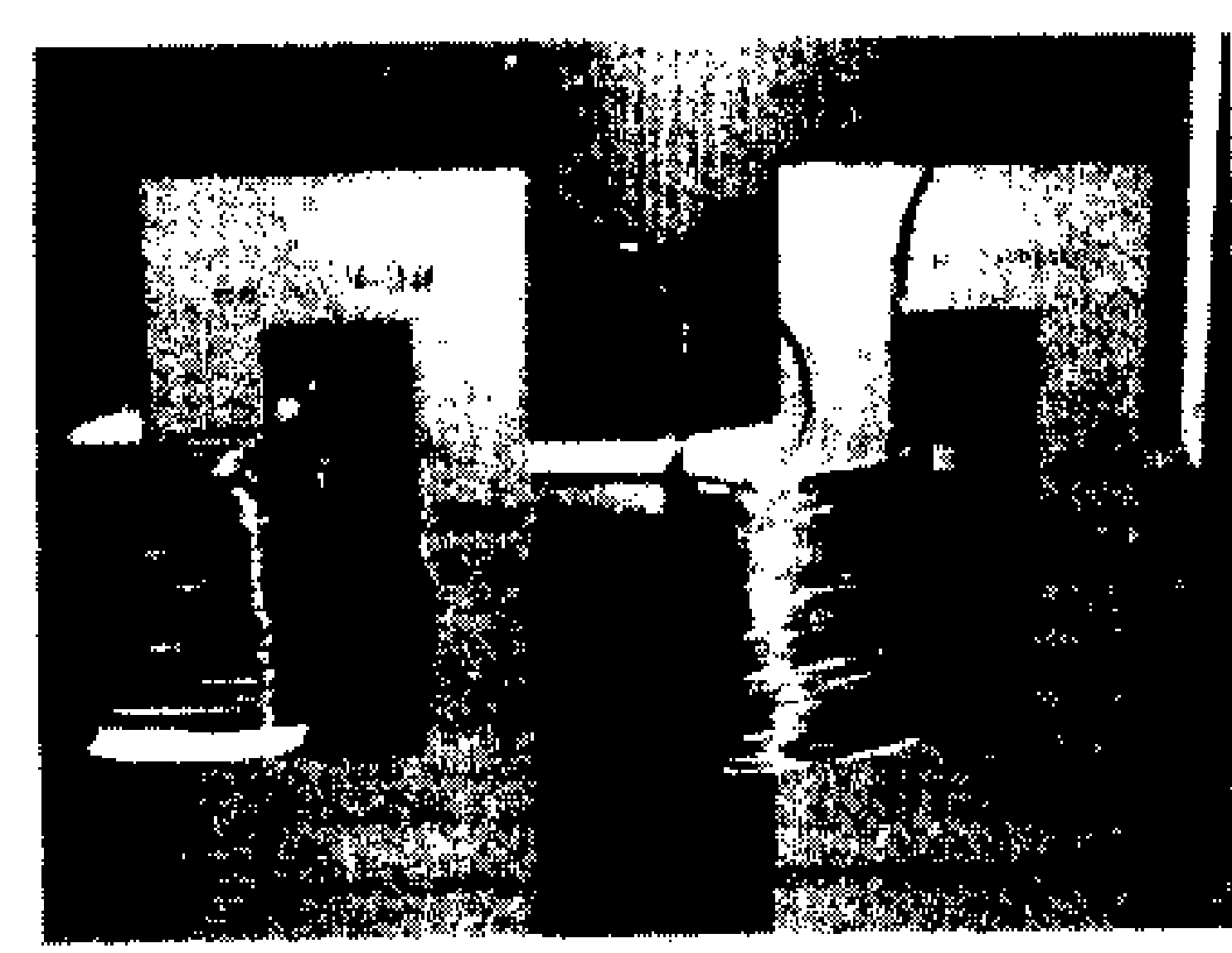

Fig. 2. Fabricated series-biased ferrite core based MCL.

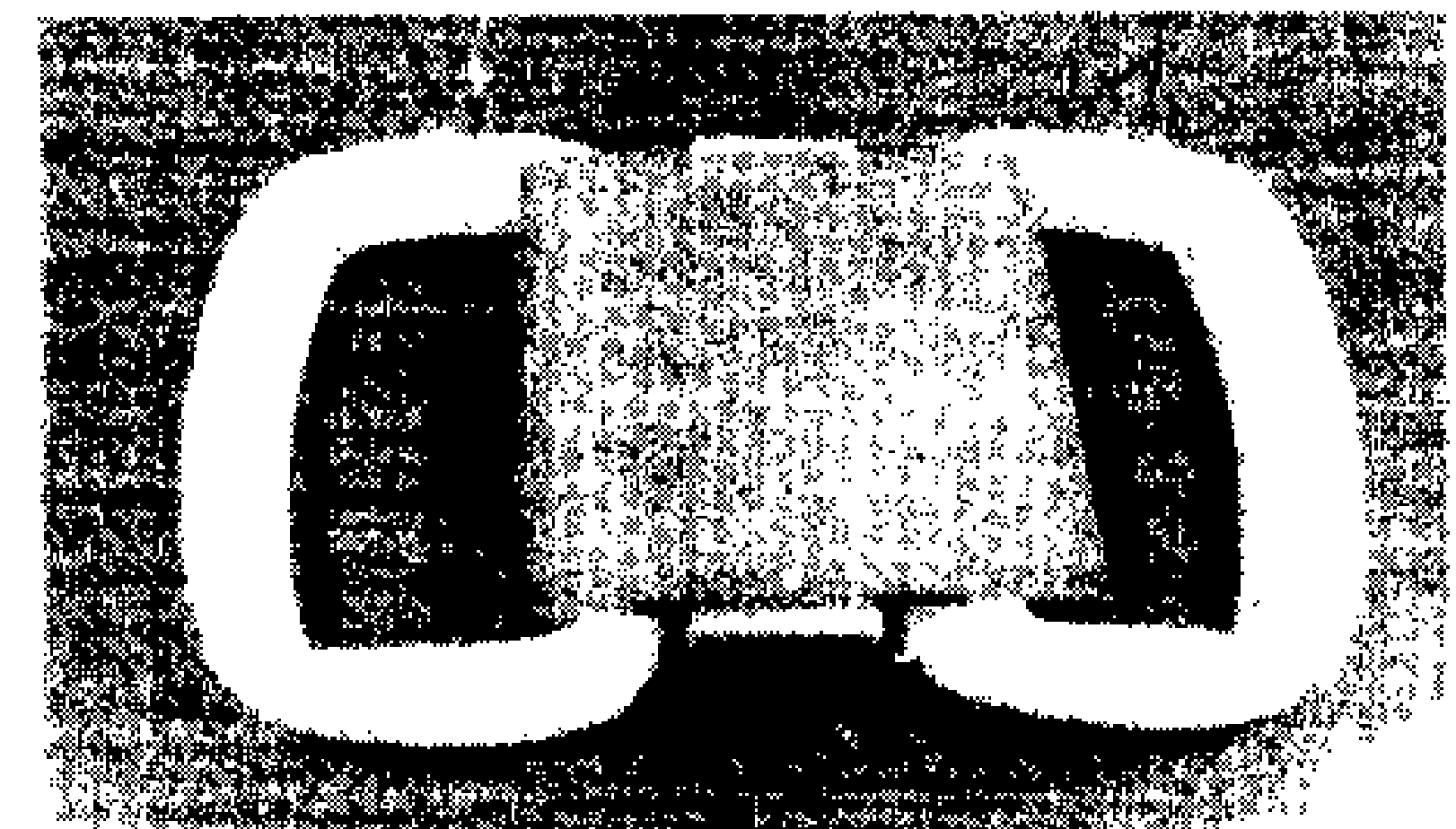

Fig. 4. Fabricated parallel-biased based MCL.

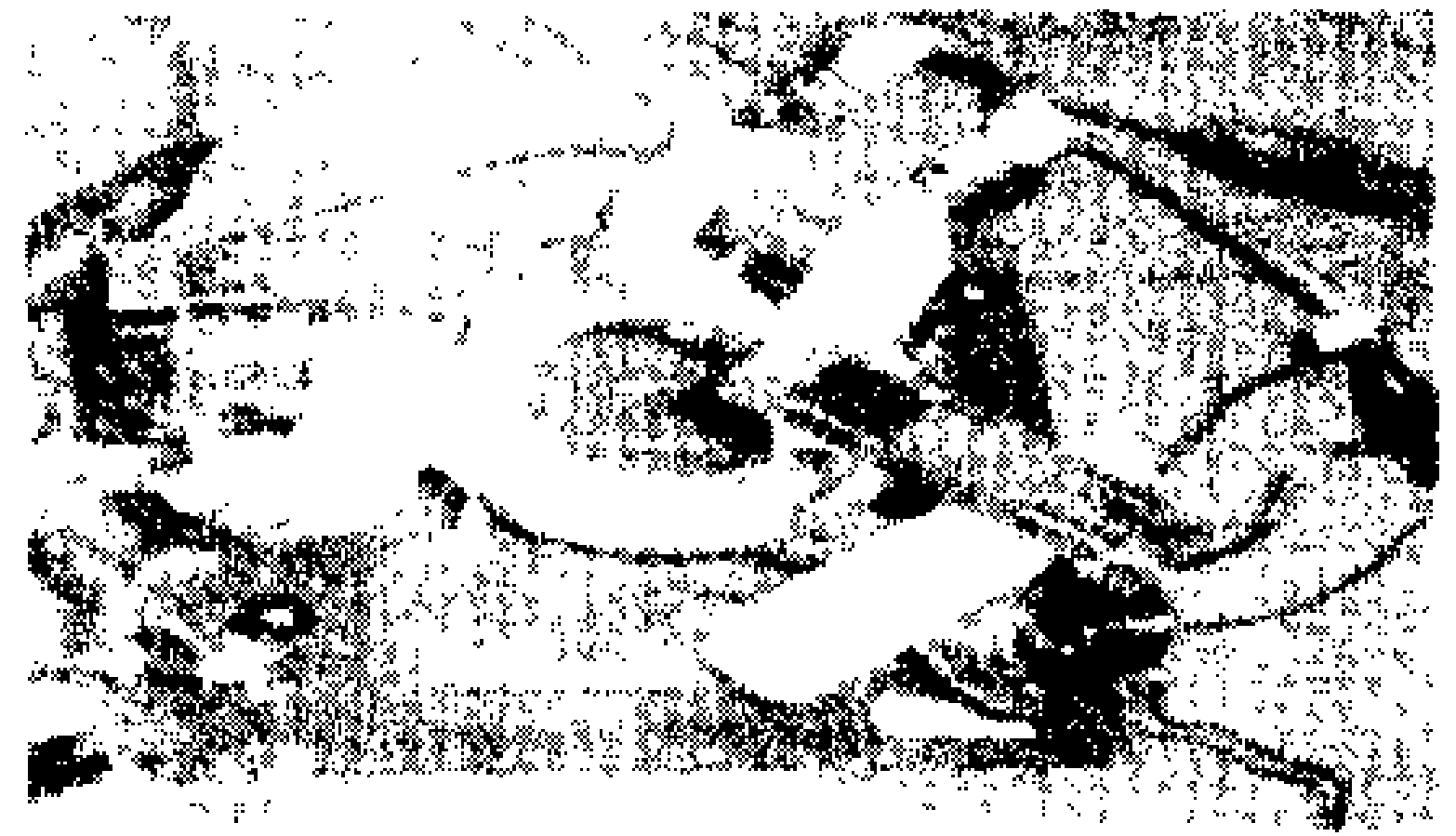

Fig. 5. Fabricated half-assembly of MCL for 3-o system.

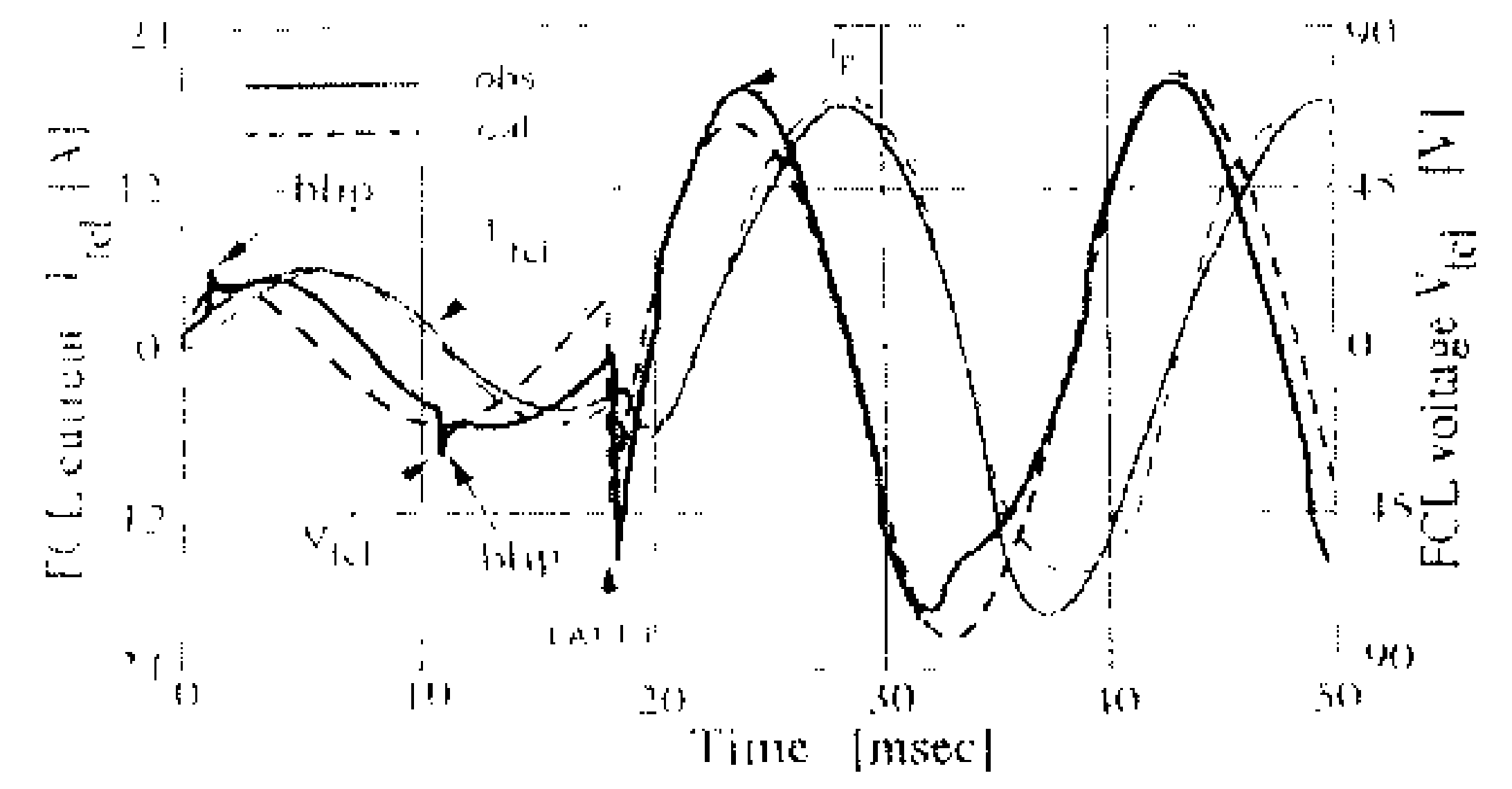

Fig, 6. Comparison of experimental and simulation results.

simulated and experimental results for a typical operating condition for the fabricated model shown in Fig. 2. It can be seen there are blips in the experimental voltage waveform across the limiter even under normal operating condition. The discrepancy between the observed results and the simulation results can be attributed to a nonuniform flux distribution in the core. This effect cannot be taken into account in the lumped circuit model. In order to understand the above effect it is necessary to study the flux distribution in the core and the permanent magnet and for that reason electromagnetic field distribution has been carried out with the help of finite element method.

\section{Field distribution and remedial measures}

Figure 7 shows one quarter of the model taken for the analysis. The analysis of magnetic field in the core and magnet has been carried out using the software package JMAG-JVISION [4]. Three different PM thickness of values $0.5 \mathrm{~mm} .1 .0 \mathrm{~mm}$ and $2.2 \mathrm{~mm}$ have been taken for the analysis. Figure 8 shows the distribution of the flux lines in the assembly for a $2.2 \mathrm{~mm}$ PM thickness. From the figure it is seen 


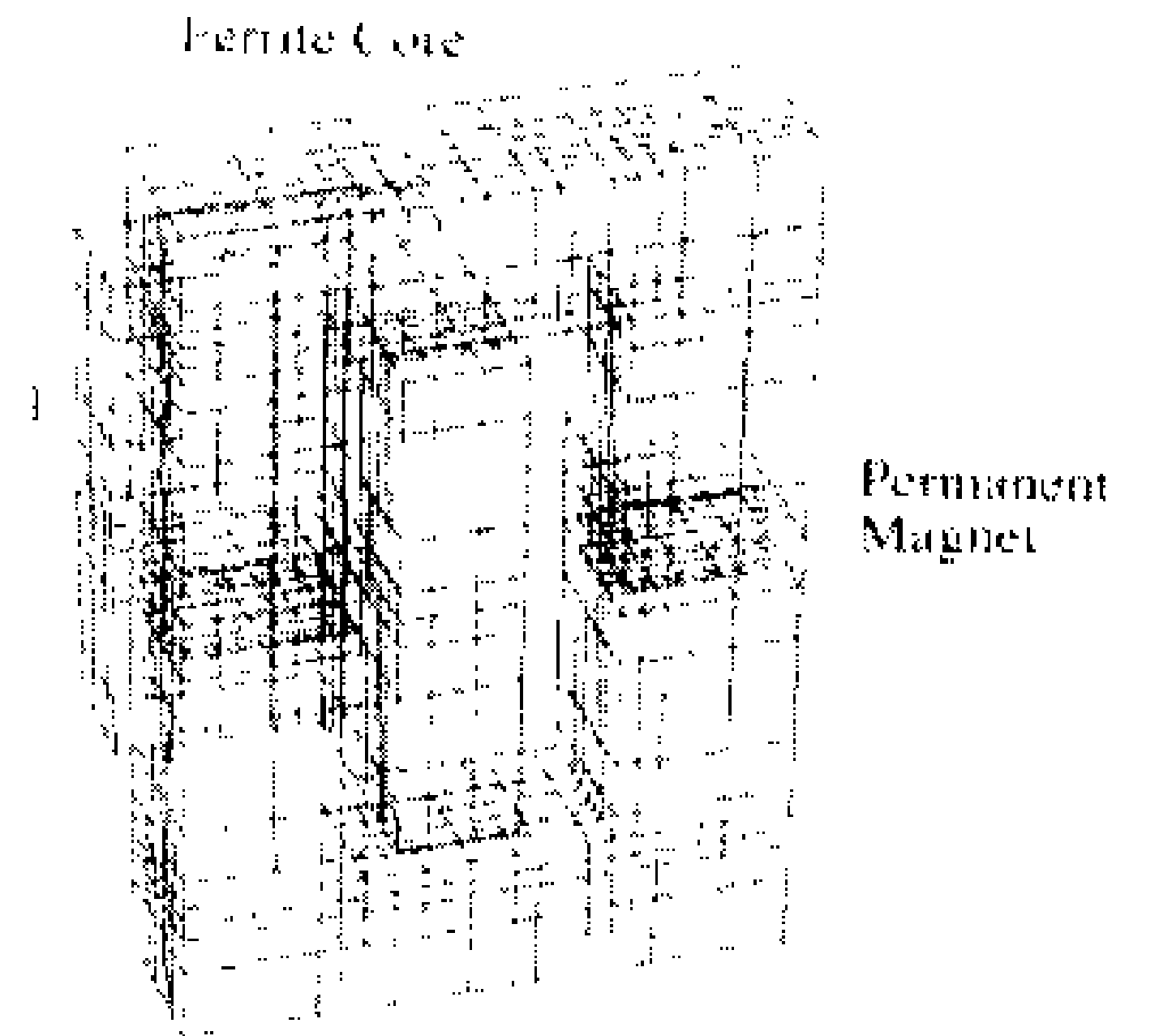

Fig. 7. FE mesh of the quarter section of the model.

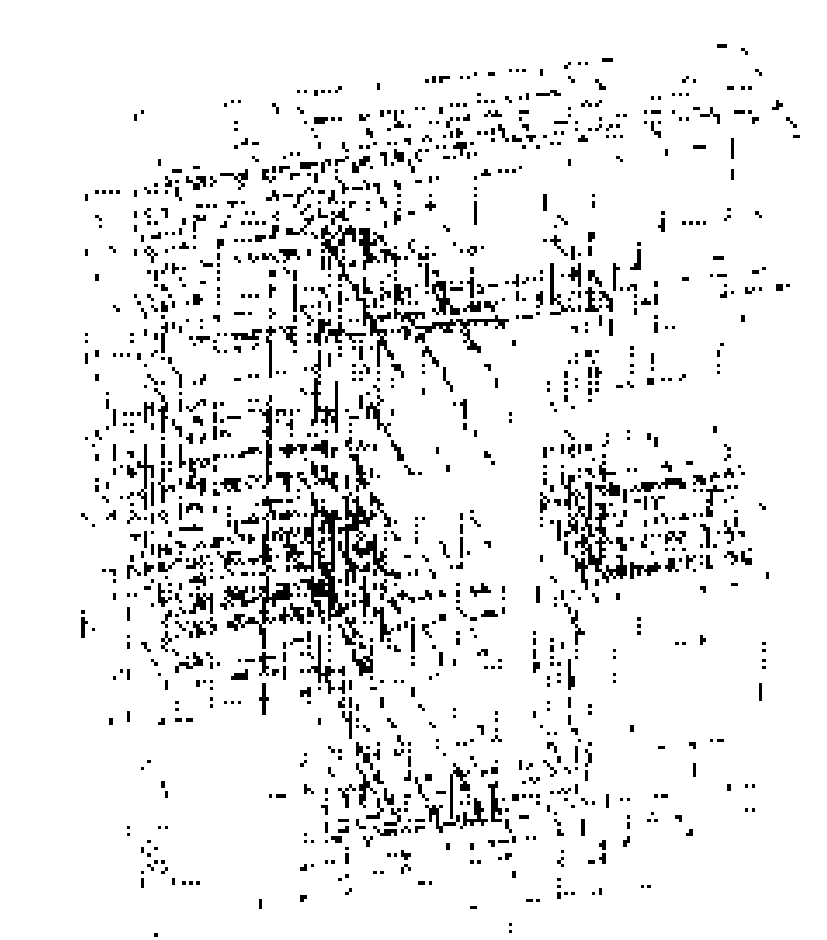

Fig. 8. Flux distribution in the assembly.

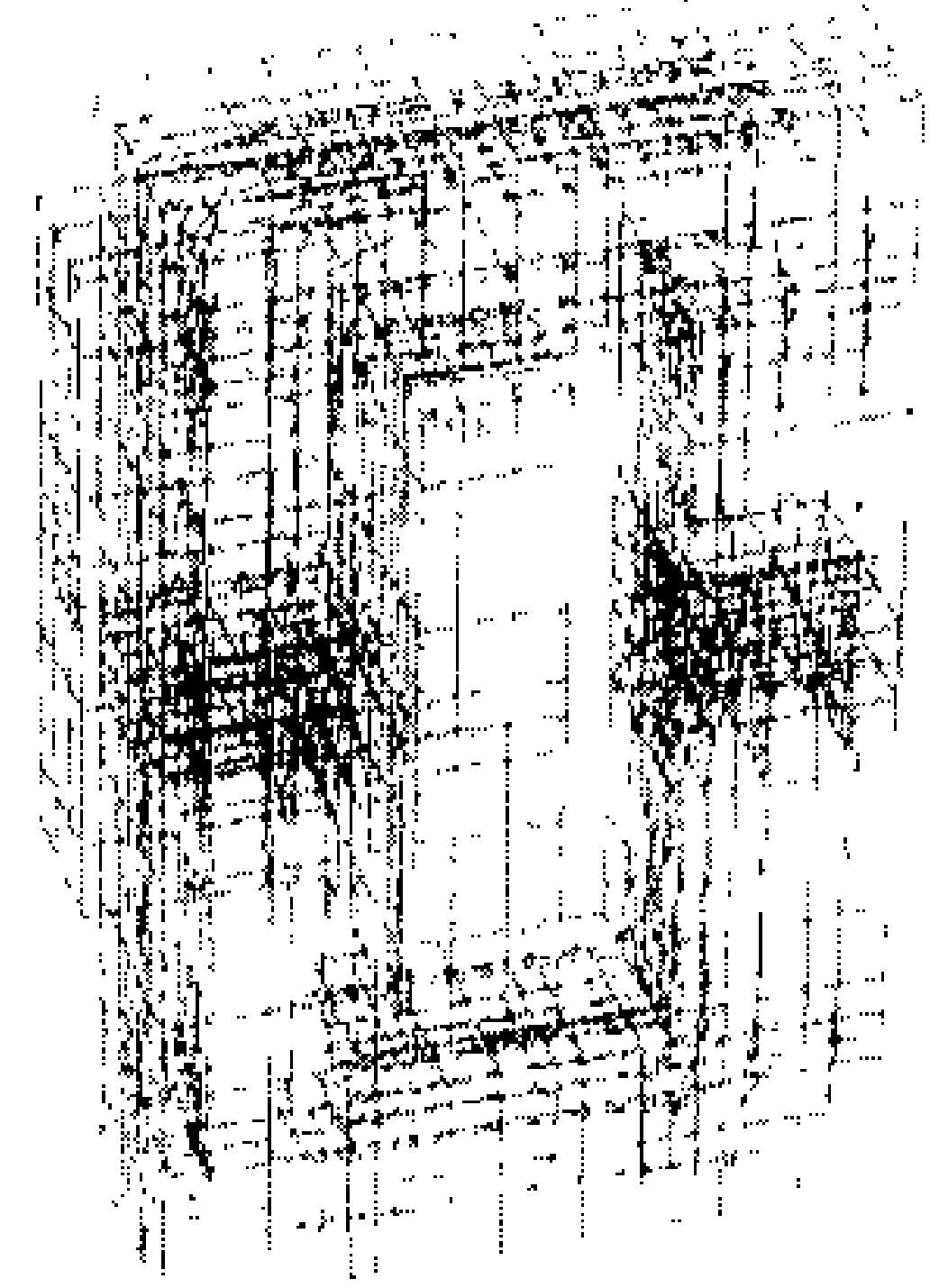

Fig. 9. Current distribution in the assembly.

Table 1

Magnetic vector potential in the PM

\begin{tabular}{llll}
\hline Magnetic vector & \multicolumn{3}{c}{ Permanent magnet length } \\
\cline { 2 - 4 } potential $(\mathrm{Wb} / \mathrm{m})$ & $2.2 \mathrm{~mm}$ & $1.0 \mathrm{~mm}$ & $0.5 \mathrm{~mm}$ \\
\hline Minimum & 0.393237 & 0.32622 & 0.27412 \\
Maximum & 0.5924 & 0.48233 & 0.3906 \\
\hline
\end{tabular}

that the flux lines are crowded in the outer section forcing the inner section to come out of saturation. Figure 9 shows the distribution of the current (i.e., the exciting current in the winding and eddy current in the core and PM) in the assembly for a $2.2 \mathrm{~mm}$ PM thickness.

From the Figs 8 and 9 it is difficult to get any idea about the relative values of the currents with the change in PM thickness. Table 1 shows the minimum and maximum values of magnetic vector potential in the PM section. It is seen that with the increase of the PM thickness the value of the magnetic vector potential in the magnet increased. This is due to the effect of higher mmf available from the PM. The magnetic reluctance of the PM increases with the thickness but the total reluctance of the magnetic circuit is not increasing proportionally.

Table 2 shows the minimum and maximum values of magnetic vector potential in the core section. It is seen that with increase of PM thickness, the value of magnetic vector potential in the core increased. But the minimum value of the magnetic vector potential has gone below to a value where the local flux-density is less than that of saturated flux-density which corresponds to a minimum magnetic vector potential of $0.1 \mathrm{~Wb} / \mathrm{m}$. This confirms that some parts of the core come out of saturation during normal 
Table 2

Magnetic vector potential in the core

\begin{tabular}{lccc}
\hline Magnetic vector & \multicolumn{3}{c}{ Permanent magnet length } \\
\cline { 2 - 4 } potential $(\mathrm{Wb} / \mathrm{m})$ & $2.2 \mathrm{~mm}$ & $1.0 \mathrm{~mm}$ & $0.5 \mathrm{~mm}$ \\
\hline Minimum & 0.13579 & 0.1176 & 0.07599 \\
Maximum & 0.39859 & 0.3966 & 0.35337 \\
\hline
\end{tabular}

Table 3

Eddy current density in the core

\begin{tabular}{lcrr}
\hline Eddy current & \multicolumn{3}{c}{ Permanent magnet length } \\
\cline { 2 - 4 } density $(\mathrm{A} / \mathrm{m} 2)$ & $2.2 \mathrm{~mm}$ & $1.0 \mathrm{~mm}$ & \multicolumn{1}{c}{$0.5 \mathrm{~mm}$} \\
\hline Minimum & $2.325 \mathrm{E}+04$ & $2.2002 \mathrm{E}+04$ & $2.1136 \mathrm{E}+04$ \\
Maximum & $3.796 \mathrm{E}+05$ & $2.227 \mathrm{E}+05$ & $1.334 \mathrm{E}+05$ \\
\hline
\end{tabular}

operation. Table 3 shows the minimum and maximum values of eddy current density in the PM section. It is seen from Tables 2 and 3 that the minimum value of magnetic vector potential increased with the increase of PM thickness but the eddy current density also increased. The effect of eddy current should be reduced to have a uniform flux distribution. One approach to reduce the effect of eddy currents in the core is, to use laminated core with material such as silicon steel. Using the approach described in [5] better results have been obtained. Since the saturation flux density of steel core is larger than the remanent flux density of the permanent magnet, the core has of two sections of different cross-sectional area. The section having smaller area is forced into saturation by the PM $\mathrm{mmf}$ and is important in limiting the fault current. This scheme shown in Fig. 3 is suitable for lower capacity systems. Another approach is to use laminated permanent magnet without sacrificing the available PM mmf. Without the use of any special technique this approach is difficult to fabricate in the laboratory and may require industrial support.

\section{Conclusions}

This paper has described the necessity of electromagnetic field computation of magnetic fault current limiter. Using finite element analysis the distribution of fluxes and eddy current has been analyzed for three different thicknesses of permanent magnets, $2.2 \mathrm{~mm}, 1.0 \mathrm{~mm}$ and $0.5 \mathrm{~mm}$. It has been shown that the increase in PM thickness will increase the local flux-density of the core to go beyond the saturated flux density under normal operation but this will also increase the eddy current density in the permanent magnet. One remedial measure to use laminated core has been described in the paper. The use of laminated permanent magnets is under investigation.

\section{References}

[1] S.C. Mukhopadhyay, F.P. Dawson, M. Iwahara and S. Yamada, Analysis, design and experimental results for a passive current limiting device. IEE proceeding on Electric Power Applications 146(3) (May 1999), 309-316.

[2] S.C. Mukhopadhyay, F.P. Dawson, M. Iwahara and S. Yamada, Investigation on the topological configuration of magnetic current limiter for the protection of power semiconductor devices, Proceeding of IEEE-IAS annual meeting, (Vol. 4), Rome, Italy, Oct. 8-12, 2000, pp. 2463-2470.

[3] M. Iwahara and E. Miyazawa, A numerical method for calculation of electromagnetic circuits using tableau approach, IEEE transc. on Magnetics 19(6) (Nov. 1983), 2457-2460.

[4] JMAG-JVISION - Finite Element Package: The Japan Research Institute Ltd., Tokyo, Japan, 1998.

[5] S.C. Mukhopadhyay, M. Iwahara, S. Yamada and F.P. Dawson, Investigation of the performances of a permanent magnet biased fault current limiting reactor with a steel core, IEEE transc. on Magnetics 34(4) (July 1998), 2150-2152. 